\title{
Design and Research on Creative Casting Industrial Park Based on Exterior Building Reconstruction
}

\author{
Hong Mao \\ Chongqing Vocational Institute of Engineering, Jiangjin 402260, China
}

\begin{abstract}
Keywords: Industrial buildings; external space reconstruction; creative industries; creative casting industrial park
\end{abstract}

\begin{abstract}
The reconstruction and reuse of industrial buildings has always been the focus of the architectural industry. Based on the analysis of the present transformation situation on industrial buildings in China, the paper discusses the significance of the combination between the industrial buildings and creative industry park, and combines with the example of Nanjing 1865 Creative Industry Park, explores the creative design methods of Industrial Park based on the exterior building space transformation.
\end{abstract}

\section{Introduction}

With the rapid development of our country's social economy, the process of urbanization has been promoted. The adjustment of economic and industrial structure which has led to the collapse of many traditional enterprises, a large number of industrial legacy buildings is being destroyed or demolished. How to rebuild and reuse these old industrial buildings has always been a key concern on urbanization. If we demolish these buildings, it will inevitably lead to the waste of capital and resources and a wide range of environmental pollution. Also its transformation, we should combine urban development needs, in line with the concept of economy and environmental protection. Creative industries belong to a new type of industrial mode that has certain cultural connotations, with advanced technologies and technologies and gives full perspective to human creativity. It is also a new growth point for the national economy. With the development of creative industries, various forms of creative industrial parks have emerged around the country, stimulating the public's enthusiasm for innovation. In this context, the legacy industrial buildings and creative casting industrial park design combined, through the overall planning and space transformation of the old industrial buildings, creatively tap the potential of its application, the formation of a creative and aesthetic characteristics of the industrial base, Not only can promote the "new life" of the old factory area, but also provide creative workers with more ideal working places, which further ensure the diversity of urban space.

\section{The Significance of Combining Industrial Architecture with Creative Industry Park in China}

With the acceleration of urban modernization, many abandoned industrial buildings are facing the risk of being destroyed due to the loss of their existing functions. These modern architecture, built more than the middle of the last century to the founding of New China, especially in the period of China's planned economy, there have been many historic buildings, but also has the urban atmosphere of industrial buildings, they witnessed the development course of industrialization in China which should be paid attention and protection. Although the renovation of old industrial buildings has been carried out in many areas in our country since the 1990s, it has achieved some success. However, compared with the western countries, our country still has many problems for remodeling the legacy buildings, such as the single form of transformation and the inability to reflect the value of the building itself. In many parts of our country, there are limitations in industrial building renovation, ignoring the integration with the ecological environment and local landscape culture. Many policymakers are quick successors in the process of transformation, neglecting to evaluate the value of architectural culture, being unable to loyalty to the original history of industrial 
buildings, or lacking in creativity, making the reformed buildings have a single function and can not meet the needs of the creative industries.

Creativity is a new idea that can be seen as a distinctive design, scheme, or invention, with novelty and effectiveness. The creative industry is based on the individual creativity, and through the pursuit of innovation to realize the promotion and support of the marketization. It is a new form of social and economic development. Peter, a famous German economist, firstly proposed this idea. He believed that the impetus for the development of modern economy is not labor, but innovation. In order to achieve innovation, we need to make full use of all kinds of information knowledge to promote the production, dissemination and utilization of information. The essence of the creative industry is to give things new functions or features through innovation. Creative Industrial Park is a combination of work, communication and entertainment, covering production casting, education and training, leisure and entertainment, art design and other industries. In order to meet the needs of coexistence and prosperity of different creative industries, creative industrial parks need to design various functional spaces, and reconstruct some functions through the rational planning and transformation of existing buildings, thus forming a creative base for different enterprises and groups. Looking at the development of creative industries both at home and abroad, we can see that building creative industrial parks can not only stimulate individual creativity, but also promote innovative urban thinking, and promote the renewal of urban functions, as shown in Figure 1 below.

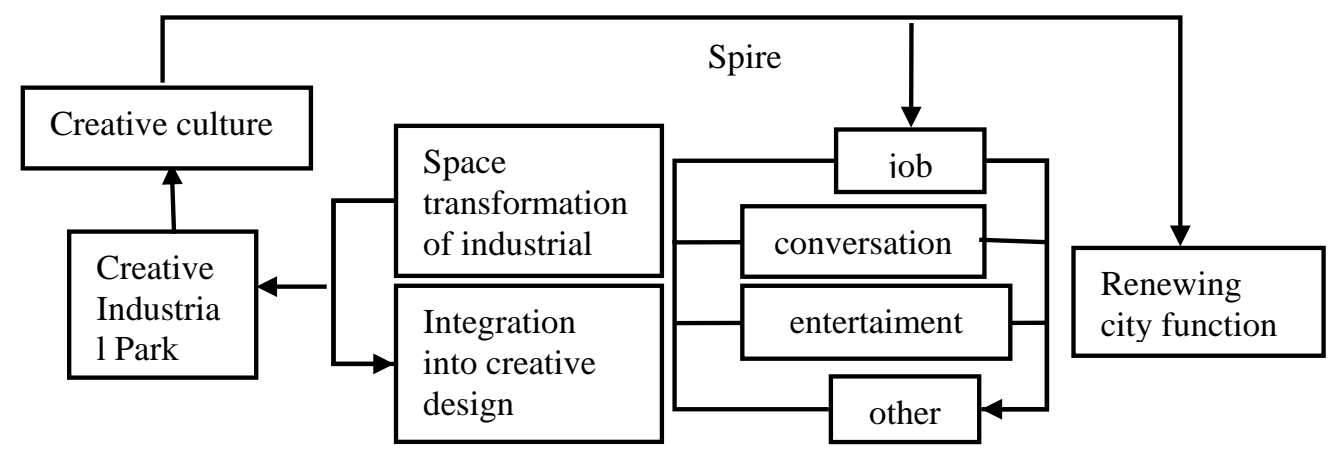

Fig. 1 The renewal function of the city in the creative industry

Creative industries belong to a new type of economic model with very high added value, which is of great significance to the adjustment of industrial structure in our country and the optimization of urban hardware functions. With the improvement of the country's emphasis on creative industries, various localities have promulgated corresponding policies aimed at promoting the development of creative industries. However, creative industries need to build a well-functioning industrial park and create a good creative environment. Making old industrial buildings into creative industrial parks can not only solve the problem of land occupation of old buildings, but also be a good way to transform urban space. The life span of industrial buildings is divided into two parts: structure and function. When the factory is relocated or collapsed, its functional life is over, and its renovation and redesign will give it a brand new functional life. Our country belongs to the country with more construction land. Each year, the new construction area exceeds 100 million square meters, consuming a lot of steel and cement. The reconstruction of old industrial buildings will not only save construction funds, avoid the resulting environmental pollution, but also create more new creative industrial parks. Nowadays, in the process of urbanization in Europe and the United States, a path of sustainable development has emerged through the transformation and reuse of old buildings. Our country should also draw on the successful experience of other countries and make contributions to the urban environmental protection through the preservation and transformation of industrial buildings. 


\section{Design of Creative Foundry Industrial Park Based on Reconstruction of Building Exterior Space}

The creative foundry industry park is the creative industry base, which takes the foundry industry as the main body and the other industries as the auxiliary. Based on the example of the 1865 Creative Industrial Park in Nanjing, the author explores the creative design path of the Foundry Industrial Park Based on the reconstruction of the exterior space of the building.

Through the analysis of 21 converted buildings in the 1865 Creative Industry Park, it is found that the renovation focuses on different points, as shown in Table 1 . The focus of the particularity of the building requires the designer to carry out a comprehensive design of the transformation of its external space, highlighting the characteristics of the building, basically maintaining the texture and context of the original building and shaping a brand new external image. By designing transitional spaces within the complex, the exhibition will show the old and new signs of the focal building to the public and enhance the cultural heritage of the building itself, making it a window for foreign exchange in the park. The interface expansion method is less used in the reconstruction of the external space of the building due to the large cost required. The façade renewal allows the design of the building to be partially renewed on the basis of preserving the architectural features and adding new building materials such as glass and steel to contrast with the original building and make the building a completely new look. For buildings that are seriously damaged or not highly appreciated by the outside, vertical greening can be used to create a viable external building texture and change the cold visual experience of the external walls.

Table 11865 method statistics of the external space transformation of various buildings in the Creative Industrial Park

\begin{tabular}{lcccc}
\hline \multicolumn{1}{c}{ Transformation method } & Number & $\begin{array}{c}\text { Focus } \\
\text { building }\end{array}$ & $\begin{array}{c}\text { Plastic } \\
\text { building }\end{array}$ & $\begin{array}{c}\text { Typical } \\
\text { building }\end{array}$ \\
\hline Comprehensive transformation & 4 & $75 \%$ & $25 \%$ & \\
Interface development & 6 & $50 \%$ & $50 \%$ & \\
Facade update & 9 & $50 \%$ & $50 \%$ & \\
$\begin{array}{l}\text { Entrance reconstruction } \\
\text { Total }\end{array}$ & 2 & & & $100 \%$ \\
\hline
\end{tabular}

The design and updating of the external space of industrial buildings, if only rebuilt according to the existing frame structure of the building, ignoring the industrial characteristics of the building itself will not only affect the public's cognition of familiar places but also destroy the original society of the building Organizational function, which in turn leads to a breakdown of the urban context or memory heritage. Therefore, in the process of transforming industrial buildings into creative casting industrial parks, not only the design needs to be based on the space needs of the creative industries, but also the unique industrial features of the buildings need to be preserved so that they have historical and ornamental value. Designers use façade update approach to highlight the original industrial features of the building, a single building should also focus on reflecting its characteristics. The effective treatment of the details of the industrial building can not only preserve the industrial historical memory of the building itself, but also achieve the purpose of continuing the urban culture. As many old industrial buildings are old, their external walls, with normal weathering, have changed in color, material, and structure, leaving traces of time. In the process of renovation, the external wear of the building should be preserved, the old parts should not be changed, and the role of historical marks should be reflected. For those buildings with high historical and cultural value, but with serious external damage, the restored buildings can be cleaned up and the special features such as beam columns and walkways can be designed to restore the original appearance of the building.

Along with the increasing number of creative industrial park, building designers of industrial architecture external morphology transformation and the assurance of pair of industrial architecture is more mature, also pay attention to balancing the needs of urban memory extending. But in the reform of the industrial buildings, there are few designers take into account the design method of low energy consumption, especially by the creative industry organize build creative industry park. Since last century, many of the industrial building, and there are differences in today's architecture of 
advocating green, environmental protection, the outer enclosure with internal structure rarely satisfy the standard of low energy consumption. In turn them into creative YuanHou casting industry, will have to use the central air conditioning equipment, not only to increase the cost, it is easy to cause environmental pollution. Therefore, in the reconstruction of industrial buildings in outer space, can undertake external wall retaining structure design low energy consumption. As the external the main structure of industrial architecture, by increasing the external wall thermal inertia, enhance the overall heat preservation and heat insulation of the building ability, exert the function of adjusting indoor temperature. 1865 parts of the creative industrial park construction, the designers in the process of modification, adopted the method of improve exterior wall insulation, through in the exterior parts of the existing pile concrete bricks, and inside the wall add rock wool insulating layer, ensure the wall heat preservation after modified in accordance with national standards. To avoid due to the increased wall thickness, lead to the use of building area reducing, the designers more options heat preservation performance is good material, in improve the whole thermal inertia of buildings at the same time, reduce the use of building area. The material divided into two categories, insulation and heat preservation, performance comparison shown in Table 2.

Table 2 Performance comparison of internal and external insulation materials of building walls

\begin{tabular}{|c|c|c|c|}
\hline Category & Strenghen & weakness & Scope of application \\
\hline $\begin{array}{l}\text { Internal } \\
\text { Heat } \\
\text { preservation }\end{array}$ & $\begin{array}{l}\text { It is not disturbed by } \\
\text { external factors. } \\
\text { A temperature rise } \\
\text { block for heating. }\end{array}$ & $\begin{array}{l}\text { Condensate is easily produced } \\
\text { in the insulating layer. } \\
\text { The thermal stability is poor } \\
\text { in intermittent heating. }\end{array}$ & $\begin{array}{l}\text { The space transformation } \\
\text { applicable to the maintenance } \\
\text { of the building facade }\end{array}$ \\
\hline $\begin{array}{l}\text { External } \\
\text { heat } \\
\text { preservation }\end{array}$ & $\begin{array}{l}\text { It can protect the main } \\
\text { Structure of exterior wall. } \\
\text { The thermal stability is } \\
\text { good, and the condensate } \\
\text { is less in the insulation } \\
\text { layer. }\end{array}$ & $\begin{array}{l}\text { It is located in the external } \\
\text { insulation layer and needs } \\
\text { special protection. There is } \\
\text { an impact on the facade of } \\
\text { the building. }\end{array}$ & $\begin{array}{l}\text { The space transformation } \\
\text { suitable for the redesign of } \\
\text { the building facade }\end{array}$ \\
\hline
\end{tabular}

\section{Summary}

In the design of creative foundry industrial park based on industrial building renovation, designers not only undertake the function of re-planning and transforming original space, but also bear the heavy responsibility of extending the urban context and preserving the historical heritage. Therefore, designers should make full use of the cultural value of the existing buildings in the reconstruction of the external space of the buildings. Under the premise of respecting the historical and cultural backgrounds of the buildings themselves, designers should choose reasonable design methods in accordance with the actual conditions and then give the new functions of industrial buildings and Connotation.

\section{References}

[1] Giurco D, Cohen B, Langham E, et al. Backcasting energy futures using industrial ecology[J]. Technological Forecasting \& Social Change, 2011, 78(5):797-818.

[2] Peterson R E, Sullivan M R. Prefabricated, prefinished reinforced panels for building exterior and interior surfaces and method of manufacture: US, US8006448[P]. 2011.

[3] Bozsaky D. Application of Nanotechnology-Based Thermal Insulation Materials in Building Construction[J]. Slovak Journal of Civil Engineering, 2016, 24(1):17-23.

[4] Huang K T, Liu F R, Liang H H, et al. Design and Energy Performance of a Buoyancy Driven Exterior Shading Device for Building Application in Taiwan[J]. Energies, 2015, 8(4):2358-2380. 
[5] Ömer Akin. Case-based instruction strategies in architecture[J]. Design Studies, 2002, 23(4):407-431.

[6] Xie Dixiang, Chen Huiqi, Deng Yawen. Planning study on the cultural and creative industial parks in the context of industrial heritage reuse. Industrial Construction, 2013, 43(3): 36-39. (In Chinese). 